\title{
DIRECTED VS REGULAR DIFFUSION STRATEGY: EVOLUTIONARY STABILITY ANALYSIS OF A COMPETITION MODEL AND AN IDEAL FREE PAIR
}

\author{
MD. KAMRUJJAMAN
}

\begin{abstract}
In this study, we consider a reaction-diffusion competition model describing population dynamics of two competing species and the interactions between them in a heterogeneous environment. The main goal of this paper is to study the impact of different diffusion strategies on the outcome of competition between two populations while the first species is distributed according to the resource function and the second population is following the regular dispersion. We focus on how directed diffusion in the habitat influences selection. The two populations differ in the diffusion strategies they employ as well as in their environmental intensities. We establish the main results which determine that the competing species may either coexist, or one of them may bring the other to extinction. If higher carrying capacity is incorporated for the directed dispersal population then competitive exclusion of a regularly diffusing population is inevitable. We consider the case when both populations manage to coexist and there is an ideal free pair with identical carrying capacity, and the relevant coexistence equilibrium is a global attractor. The coexistence solution is also presented by showing the influence of diffusion coefficients. In a series of examples, the results have been justified and illustrated numerically.
\end{abstract}

Mathematics subject classification (2010): 92D25, 35K57, 35K50, 37N25.

Keywords and phrases: Diffusion strategy, competition, coexistence, semi-trivial equilibria.

\section{REFERENCES}

[1] Y. Morita AND K. TAChibana, An entire solution to the Lotka-Volterra competition-diffusion equations, SIAM J. Math. Anal., 40, 6 (2009), 2217-2240.

[2] R. S. CANTrell And C. Cosner, Spatial Ecology via Reaction-diffusion Equations, Wiley Series in Mathematical and Computational Biology, John Wiley \& Sons, Chichester, 2003.

[3] J. Dockery, V. Hutson, K. Mischaikow, M. Pernarowski, The evolution of slow dispersal rates: a reaction diffusion model, J. Math. Biol., 37, 1 (1998), 61-83.

[4] S. Williams AND P. ChOW, Nonlinear reaction-diffusion models for interacting populations, J. Math. Anal. Appl., 62 (1978), 157-159.

[5] A. LEUnG, Limiting behaviour for a prey-predator model with diffusion and crowding effects, J. Math. Biol., 6 (1978), 87-93.

[6] X. Q. He AND W. M. NI, The effects of diffusion and spatial variation in Lotka-Volterra competitiondiffusion system I: Heterogeneity vs. homogeneity, J. Differential Equations, 254, 2 (2013), 528-546.

[7] K. Kishimoto AND H. F. Weinberger, The spatial homogeneity of stable equilibria of some reaction-diffusion systems on convex domains, J. Differential Equations, 58 (1985), 15-21.

[8] M. Mimura, S. I. EI AND Q. FANG, Effect of domain-shape on the coexistence problems in a competition-diffusion system, J. Math. Biol., 29 (1991), 219-237.

[9] K. Y. LAM AND W. M. NI, Uniqueness and complete dynamics in heterogeneous competitiondiffusion systems, SIAM J. Appl. Math. 72 (2012), 1695-1712.

[10] V. HUtSON, K. MischaIKOW, AND P. POLACIK, The evolution of dispersal rates in a heterogeneous time-periodic environment, J. Math. Biol., 43, 6 (2001), 501-533.

[11] I. AVERILl, Y. LOU, AND D. Munther, On several conjectures from evolution of dispersal, J. Biol. Dyn., 6, 2 (2012), 117-130. 
[12] R. S. Cantrell, C. Cosner, Y. Lou, Approximating the ideal free distribution via reactiondiffusion-advection equations, J. Differential Equations, 245, 12 (2008), 3687-3703.

[13] R. S. Cantrell, C. Cosner, Y. Lou, Evolution of dispersal and the ideal free distribution, Math. Biosci. Eng., 7, 1 (2010), 17-36.

[14] R. S. Cantrell, C. Cosner, D. L. Deangelis And V. Padron, The ideal free distribution as an evolutionarily stable strategy, J. Biol. Dyn., 1, 3 (2007), 249-271.

[15] R. S. CANTREll, C. COSNER, Y. Lou , Evolutionary stability of ideal free dispersal strategies in patchy environments, J. Math. Biol., 65, 5 (2012), 943-965.

[16] E. BRAVERMAN AND L. BRAVERMAN, Optimal harvesting of diffusive models in a non-homogeneous environment, Nonlin. Anal. Theory Meth. Appl., 71 (2009), e2173-e2181.

[17] L. KorobenKo AND E. BRAVERMAn, On logistic models with a carrying capacity dependent diffusion: stability of equilibria and coexistence with a regularly diffusing population, Nonlinear Anal. B: Real World Appl., 13, 6 (2012), 2648-2658.

[18] L. KorobenKo AND E. BRAVERMAN, On evolutionary stability of carrying capacity driven dispersal in competition with regularly diffusing populations, J. Math. Biol., 69, 5 (2014), 1181.

[19] E. Braverman, MD. Kamrujuaman and L. Korobenko, Competitive spatially distributed population dynamics models: does diversity in diffusion strategies promote coexistence?, Math. Biosci., 264 (2015), 63-73.

[20] Piero De Mottoni, Qualitative analysis for some quasilinear parabolic systems, Inst. Math. Polish Acad. Sci., (1979).

[21] E. BRaverman AND Md. Kamrujuaman, Competitive-cooperative models with various diffusion strategies, Comp. Math. with Appl., 72 (2016), 653-662.

[22] E. Braverman And Md. Kamrujuaman, Lotka systems with directed dispersal dynamics: Competition and influence of diffusion strategies, Math. Biosci., 279 (2016), 1-12.

[23] S. B. Hsu, H. L. Smith And P. Waltman, Competitive exclusion and coexistence for competitive systems on ordered Banach spaces, Trans. Amer. Math. Soc., 348, 10 (1996), 4083-4094.

[24] K. - Y. LAM AND D. MUNTHER, A remark on the global dynamics of competitive systems on ordered Banach spaces, Proc. Amer. Math. Soc., 144 (2015), 1153-1159.

[25] M. H. Protter, H. F. Weinberger, Maximum Principles in Differential Equations, Prentice-Hall, Inc., Englewood Cliffs, N.J. (1967).

[26] D. Gilbarg, N. S. Trudinger, Elliptic Partial Differential Equations of Second Order, second edition, Springer-Verlag, Berlin, (1983). 